\title{
Fracking under the microscope
}

SIMON EMMANUEL, YEVGENY KREISSERMAN, HAN ZHANG

The Hebrew University of Jerusalem, simonem@cc.huji.ac.il

During hydraulic fracturing large volumes of water are injected into subsurface shale formations. This injected fluid can interact with different phases present within the reservoir rock, potentially leading to mineral dissolution and the mobilization of colloidal particles. Critically, both these processes can impact the composition of flowback water and the permeability of the reservoir. In our study, we use a combination of high resolution scanning electron microscopy and atomic force microscopy to show how shale composition affects the release of particulate pyrite during fluid-rock interaction. Our results show that the presence of reactive calcite tends to mobilize pyrite colloids, while organic matter, particularly bitumen, acts to bind particles to the shale matrix. We also examine how these processes affect the structure and permeability of fracture walls, and discuss the implications for oil and gas production during fracking operations. 